\title{
BACIAS URBANAS: INTERVENÇÃO ANTRÓPICA, CONSEQUÊNCIAS E PLANEJAMENTO
}

Nome do Autor (a) Principal

\section{Maíra Brito Tavares}

Nome (s) do Coautor (a) (s)

Joelma Costa Magno

Rafaela Braga da Silva

Instituição ou Empresa

\section{Universidade Federal do Pará}

Instituição (s) de Fomento

E-mail de contato: mairabtavares@gmail.com

Palavras-chave

Bacias Urbanas. Enchentes.Intervenção antrópica.

\section{Introdução}

"Os recursos hídricos têm sido alvo das intervenções antrópicas há longo tempo, desde o surgimento das primeiras comunidades humanas [...]. Contudo, é em tempos historicamente mais recentes que são registradas as maiores intervenções nesses recursos." (BOTELHO,2011, p.74). O principal motivo está no crescimento da população e sua concentração no meio urbano (cidades), assim aumentou-se a intensidade destas intervenções, principalmente nos rios.

O presente trabalho tem como objetivo entender o conceito e funcionamento de uma bacia urbana, mostrar como as ações antrópicas geraram consequências desastrosas (a exemplo das enchentes) e expor um planejamento como tentativa de solução para o problema das enchentes no meio urbano. Para tal, utilizou-se uma pesquisa bibliográfica a respeito do assunto abordado. 


\section{Periódica Eletrânica ISSN 1980-0827 \\ Fórum Ambiental \\ da Alta Paulista \\ Volume 11, Número 06, 2015 \\ Planejamento e Gestão dos Recursos Hídricos}

A gestão de recursos hídricos pode ser definida como a integração de projetos e atividades com o objetivo de promover a recuperação e a preservação da qualidade e quantidade dos recursos das bacias hidrográficas brasileiras e atua na recuperação e preservação de nascentes, mananciais e cursos d'água em áreas urbanas.

\section{O ciclo hidrológico}

Para entender melhor o conceito de bacia urbana, faz-se necessária uma rápida abordagem sobre o funcionamento do ciclo hidrológico. De acordo com Netto (1994, p.96)

Parte da água estocada na superfície terrestre é transferida para a baixa atmosfera por evaporação ou evapotranspiração, no caso da inclusão de perdas d'água pela transpiração das plantas. O vapor d'água contido na atmosfera até uma certa altitude pode ser condensado em função do próprio rebaixamento de temperaturas com a altitude e também pela presença de micropartículas em suspensão que funcionam como núcleos de condensação. Quando o nível de condensação atinge uma massa crítica e as microgotículas d'água não mais conseguem se manter em suspensão no ar, ocorre a precipitação. As águas retornam à superfície na forma líquida (chuvas) ou sólida (gelo ou neve), de acordo com as condições de temperatura na sua zona de precipitação. Antes de atingir a superfície, pode ser parcialmente evaporada e/ou parcialmente interceptada pela vegetação; o restante, então, será redistribuído na superfície: o que não se infiltrar nos solos ou rochas escoará superficialmente; quanto à água infiltrada, depois de preencher o déficit de água do solo, poderá gerar um escoamento subsuperficial.

O esquema explicado também pode ser entendido a partir da imagem a seguir: 


\section{Fórum Ambiental}

Fiaura 1: O ciclo hidrolóaico

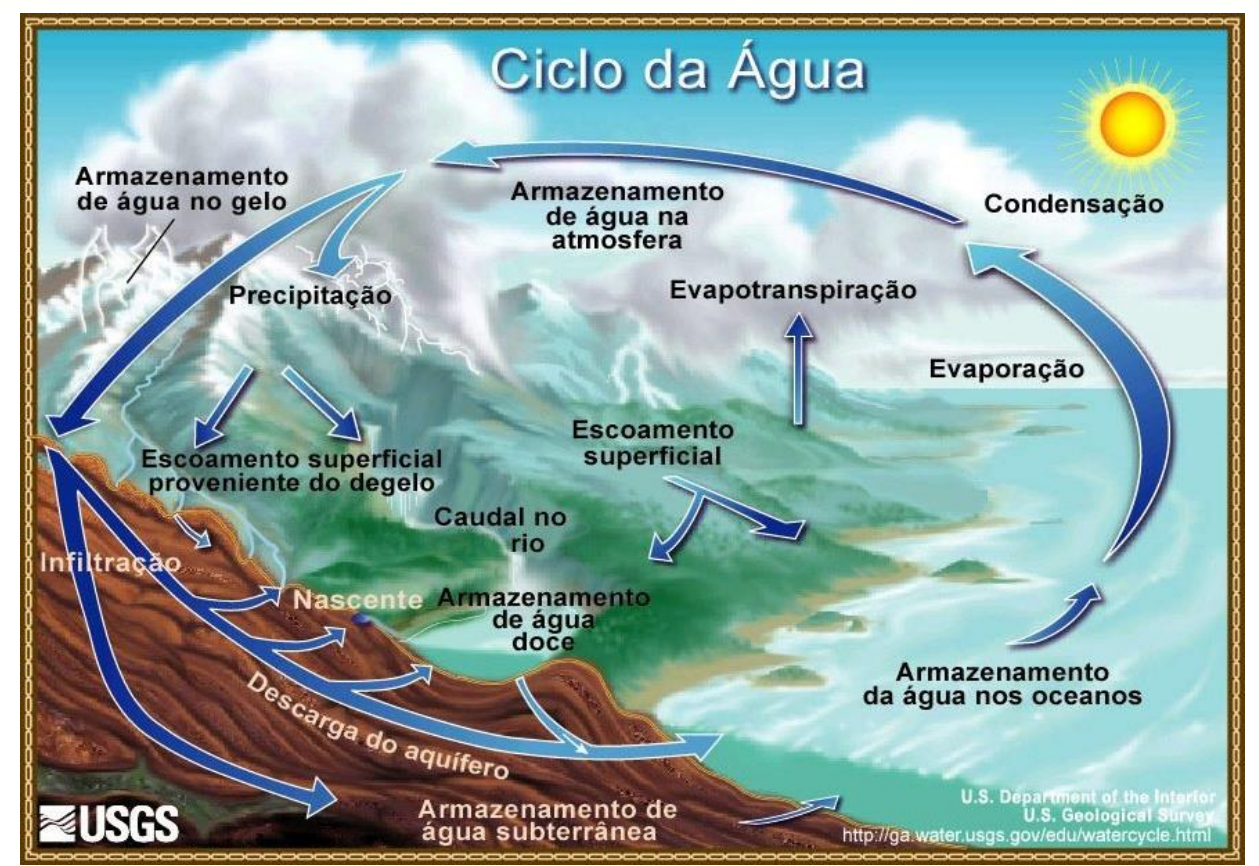

$\mathrm{Na}$ área urbana, todo o ciclo mostrado anteriormente reduz-se ao escoamento e infiltração, com maior participação do primeiro. Isso ocorre pela ausência da cobertura vegetal, que faz com que a água infiltre pouco e escoa mais rápido pelas vias pavimentadas. Como resultado principal, temos as enchentes (Botelho, 2011). "As bacias hidrográficas urbanas são, portanto, marcadas pela diminuição do tempo de concentração de suas águas e pelo aumento dos picos de cheias, quando comparadas às condições anteriores à urbanização." (BOTELHO, 2011, p.73). Além disso, soma-se a esta água as águas servidas, de uso doméstico e industrial, que pela falta de um sistema adequado de tratamento e recolhimento, são conduzidas junto com as águas pluviais, quando não são lançadas diretamente nos corpos d'água. Esta é uma prática altamente nociva pela degradação das águas e pela redução do tempo do ciclo hidrológico.

\section{Intervenções antrópicas nos cursos d'água e suas consequências}

As intervenções antrópicas nos recursos hídricos não são práticas recentes, pelo contrário, porém, é recentemente (nas últimas décadas) que foram registradas as maiores intervenções. Os principais motivos são: crescimento da população e sua concentração nas cidades e o próprio aumento destas. As principais modificações feitas pelo homem são: canalização, retificação, alargamento, afundamento e desvio. O exemplo mostrado na imagem a seguir é de um canal chamado "Canal da 


\section{Periódica Eletranica \\ Fórum Ambiental}

da Alta Paulista
Volume 11, Número 06, 2015

Planejamento e Gestão dos Recursos Hídricos

Doca", na cidade de Belém-PA, onde é mostrado o antes (quando se chamava Igarapé das Almas ou Armas) e o depois da forte intervenção humana.

Figura 2: Canal da Doca em 1935 e atualmente

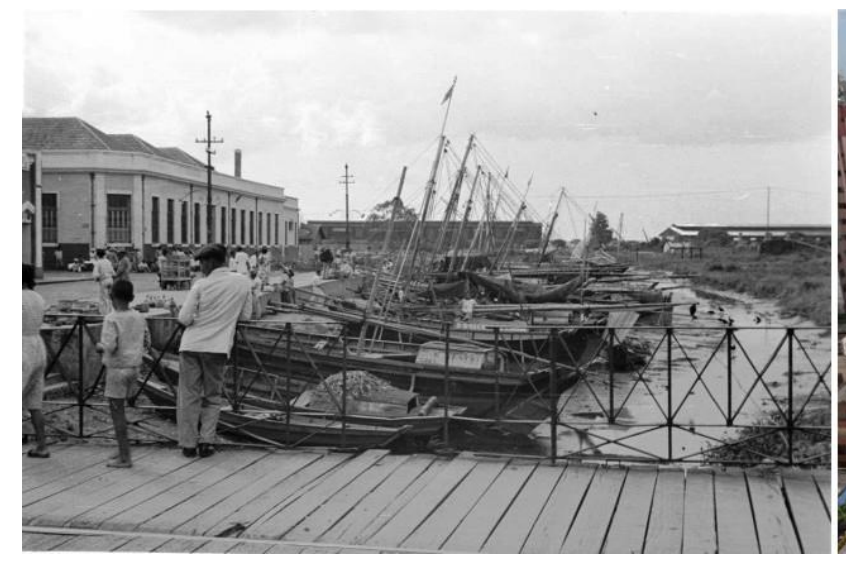

Fonte: Faculdade de Arquitetura e Urbanismo da UFPA

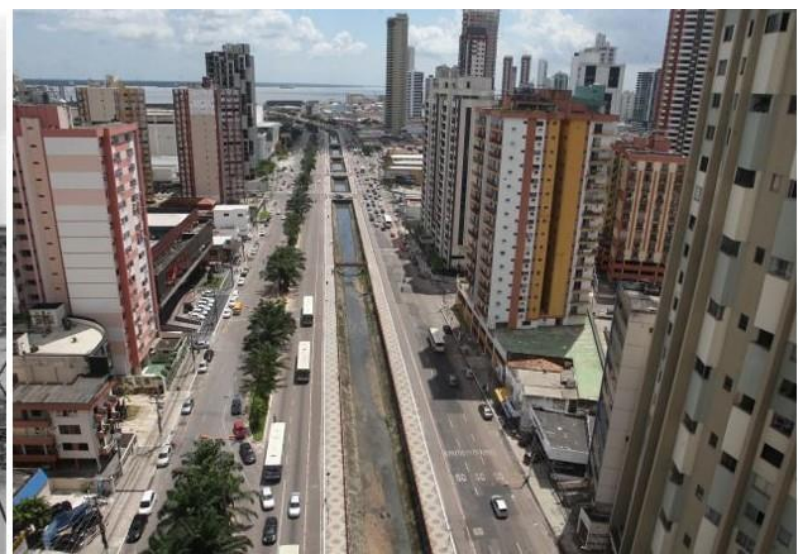

Fonte: Igor Mota/Amazônia Hoje

Na primeira foto percebe-se que o antigo igarapé das Almas ou Armas era navegável, havia a vegetação na margem do rio e a área ao redor quase não era ocupada. Já na foto atual o atual canal da Doca aparece retificado, canalizado e com seus arredores ocupados pelos edifícios no bairro em que se situa. Esse processo ocorreu em quase todo caso de uma bacia urbana, o rio que antes era natural, após as intervenções antrópicas passou a ser um rio urbano. Estas intervenções foram feitas com o objetivo de impedir as enchentes, mas ao contrário, apenas colaboraram para que elas ocorressem. Ao retificar um canal, a água vai correr com mais velocidade, erodindo e transportando os sedimentos mais rapidamente. "Ao erodir e transportar mais sedimentos, o rio irá necessariamente depositá-los a jusante, quando houver redução da declividade" (BOTELHO, 2011, p. 77). Ou seja, com mais sedimentos depositados a jusante, ocorre o risco de assoreamento e maiores são as chances das enchentes ocorrerem, voltando ao seu problema inicial. Alémdesta questão existe também a questão do lixo jogado nas ruas pelos próprios cidadãos, que agrava o problema das enchentes, pela obstrução de bueiros, bocas de lobo, etc.

Além destas tem também outras questões, Tucci (2008) aponta, por exemplo, a falta de tratamento de esgoto, onde não se tem um tratamento adequado e os efluentes são jogados diretamente nos rios como citado anteriormente; redes 
de esgotamento sanitário que muitas vezes não tem tratamento, sem a implementação de uma drenagem urbana, assim sofrendo inundações; ocupação do leito de inundação, com a consequência também da inundação.

\section{Novos caminhos a partir de um planejamento}

Diante destas várias intervenções no ambiente urbano, é necessário que haja a adoção de novos paradigmas, um novo planejamento como forma de solução (ou ao menos uma tentativa desta) para o problema das enchentes e degradação dos recursos hídricos.

Tucci (2001), citada por Botelho (2011, p.94) aponta dois tipos de medidas controle de enchentes: Estruturais e Não estruturais. As medidas Estruturais levam em consideração a alteração do homem diretamente no sistema fluvial e divide-se em Intensivas (Modificação direta no curso d’água) e Extensivas (Intervenções indiretas no sistema fluvial). As medidas Não estruturais buscam uma harmonia com os rios, onde o homem não altera seu sistema. A seguir será explicada detalhadamente cada uma.

As medidas Estruturais Intensivas tratam-se da Canalização (quando o rio é canalizado); Retificação (quando o rio "perde" seus meandros para tornar-se reto), muito cômodo para a construção de imóveis, já que os meandros dos rios ocupam espaço na superfície. Com um rio retificado, o espaço para a construção torna-se maior; Desvio de canal; diques (muros construídos para evitar o transbordamento do rio); Bacias de amortecimento (com o objetivo de infiltrar a água e diminuir seu escoamento superficial).

As medidas Estruturais Extensivas dividem-se em: Contenção de encostas (para o controle da erosão); Captação de água da chuva (além de uma significativa economia de água, torna-se aliada na substituição da infiltração nas áreas urbanas); Criação de áreas verdes (para melhor infiltração da água da chuva), com mais "verde" nas cidades, melhor a água vai infiltrar e menos irá escoar, podendo diminuir o risco de enchente; Pisos permeáveis (também para melhor infiltração e menor escoamento da água); Reuso das águas servidas (com o devido tratamento).

As medidas Não Estruturais atua mais como uma forma de ajudar a população e não interferir nos cursos dos rios. Divide-se em: Sistemas de alerta (a fim de evitar-se a ocupação em áreas indevidas), seria uma medida preventiva; 


\section{Periádica Eletranica

Planos e zoneamentos (com a mesma função da anterior); seguro enchente (medida compensatória); Educação ambiental.

Botelho (2011) aponta também outras alternativas no planejamento para a recuperação e a manutenção do equilíbrio hidrológico. Seriam a Renaturalização e Revitalização dos rios urbanos. A primeira com objetivo de trazer ao rio sua condição mais natural e/original possível, estabelecendo sua vegetação original, sua morfologia, entre outros fatores. A segunda teria como objetivo implementar ações que minimizem os impactos ambientais e que ocorra a valorização dos recursos hídricos. Ambas as medidas podem combater o problema das enchentes e trazer valorização aos rios urbanos.

\section{Conclusão}

Pôde-se perceber que buscar uma solução a curto prazo para o problema das enchentes não é fácil, pois é necessário que haja um planejamento e que este planejamento entre de fato em prática, porém muitos obstáculos são encontrados, a exemplo da renaturalização, que necessita de uma grande área para que ocorra, área esta que geralmente está ocupada pelos imóveis que localizam-se perto dos rios urbanos. Logo, é necessário que haja um cuidado especial com os recursos hídricos, pois eles sempre foram e sempre serão de grande importância para a sobrevivência do homem. Algumas medidas citadas anteriormente já existem em alguns estados brasileiros, pode ser um início de mudança e que talvez um dia o homem consiga enxergar os rios como um bem que deve ser cuidado e preservado.

\section{Referências}

GUERRA, A.J.T, BOTELHO, R.G.M, Bacias Hidrográficas Urbanas in Geomorfologia Urbana. Rio de Janeiro: Bertrand Brasil, 2011.

GUERRA, A.J.T; CUNHA, S.B, NETTO, A.L.C, Hidrologia de Encosta na Interface com Geomorfologia in Geomorfologia: Uma Atualização de Bases e Conceitos. Rio de Janeiro: Bertrand Brasil, 1994.

TUCCI, C.E.M. Desenvolvimento urbano. Estudos avançados, n.22 (63), 2008.

PORTAL EDUCAÇÃO. Gestão de Recursos Hídricos. Disponível em $<$ http://www.portaleducacao.com.br/biologia/artigos/5703/gestao-de-recursoshidricos\#ixzz2Qv8ubShL> Acesso em: 05 de jun. 2015. 